\title{
Processes and Models for Serious Game Design and Development
}

\author{
Eelco Braad ${ }^{1}$, Gregor Žavcer ${ }^{2}$, and Alyea Sandovar ${ }^{3}$, \\ ${ }^{1}$ School of Communication, Media and IT, Hanze University of Applied Sciences, Groningen, \\ The Netherlands \\ e.p.braadepl.hanze.nl \\ ${ }^{2}$ Mei:CogSci - University of Ljubljana, Ljubljana, Slovenia \\ gregoreplur.si \\ ${ }^{3}$ Department of Human and Organizational Development, Fielding Graduate University, Santa \\ Barbara, California, United States \\ asandovardemail.fielding.edu
}

\begin{abstract}
A serious game needs to combine a number of different aspects to help the end user in reaching the desired effects. This requires incorporating a broad range of different aspects in the design, stemming from a broad range of different fields of expertise. For designers, developers, researchers, and other stakeholders it is not straightforward how to organize the design and development process, to make sure that these aspects are properly addressed. In this chapter we will discuss a number of ways of organizing the design and development process and various models that support specific design decisions during this process, concluding with a discussion of design patterns for serious games.
\end{abstract}

Keywords: serious game design, game development process, design science research.

\section{Introduction}

A serious game incorporates play as well as a myriad of other aspects: motivation, learning content, feedback. For designers, developers, but also researchers and other stakeholders, it is not straightforward what steps to take from a problem statement towards a game that can be played by the intended users. This chapter provides an overview of various approaches, models, and frameworks that can be used to support the design and development of serious games.

This chapter is organized into four main sections. In the first section, we will discuss a number of important aspects pertaining to the context in which a serious game is designed and the context in which the game is intended to be used. Subsequently, we will take on a high level perspective and discuss a number of processes that are being used to design and develop serious games. In the third section, we will present a number of design models that assist in making design choices to achieve particular effects with 
the resulting game. This approach is becoming more and more formalized using a design patterns approach, which are discussed in the final section.

At the end of the chapter, a number of future research questions and suggested reading material are included.

\section{Context}

A serious game only becomes an effective tool to foster learning, promote healthy behavior, or change behavior, when it is played by players. Necessarily, playing takes place in a specific context and it is often hard for a game designer to foresee the time, place, culture, and other contextual aspects that affect the player experience. Considering this context for which a serious game is designed is therefore an important step of the design process: from this context stems an important set of specific design requirements for the serious game.

Before we can discuss particular development process frameworks or more detailed design models to support design decisions, we will first explore the context. We will do so by pointing out a number of different, and often opposing, perspectives. From a user perspective, we will start with the different views that designers and users have of the game. From a game perspective, we emphasize that they differ a large amount in the audience and purposes that they address. From a market perspective, we briefly discuss some differences between the field of entertainment and serious games.

\subsection{Differences in Designers and Users}

The MDA-framework addresses the dichotomy between designers and players by defining how the mechanics, dynamics, and aesthetics of a game work together to create the player experience [1]. The game designer is in direct control of establishing the mechanics, while the aesthetics that players perceive are separated from them in time, space, and context. Reversely, the player directly perceives the aesthetics while the mechanics can only be experienced through the dynamics of gameplay. This conceptualization of game design as a second-order design problem emphasizes the complexity of predicting how design choices affect the player experience.

Considering the possible contexts in which the game will be played during the design process, requires the designer to investigate and form a model of the intended user. As the design process itself takes place in its own context as well, designers additionally need to be aware that values of their own design context may become part of the game design. Therefore, a critical view towards the design choices and underlying design assumptions needs to be taken.

A model for providing insight into and making the transfer of values explicit for game designers is Values at Play [2,3]. Supporting current design practices and iterative processes, it helps designers identify, reflect upon, and embed their values in their designs in a conscious, rather than an unconscious, manner. The integration of ethical considerations and cultural values into the design process is further discussed in [4] and in the chapter on ethical stewardship elsewhere in this book. 
Combining the views we have discussed, we can discern the context of design and context of use around the implementation of a serious game and (see Fig. 1). This visualization extends one of the diagrams from [1], however, in order to emphasize the interactive nature of play, the relationship between the player and the serious game has been visualized as a bi-directional arrow.

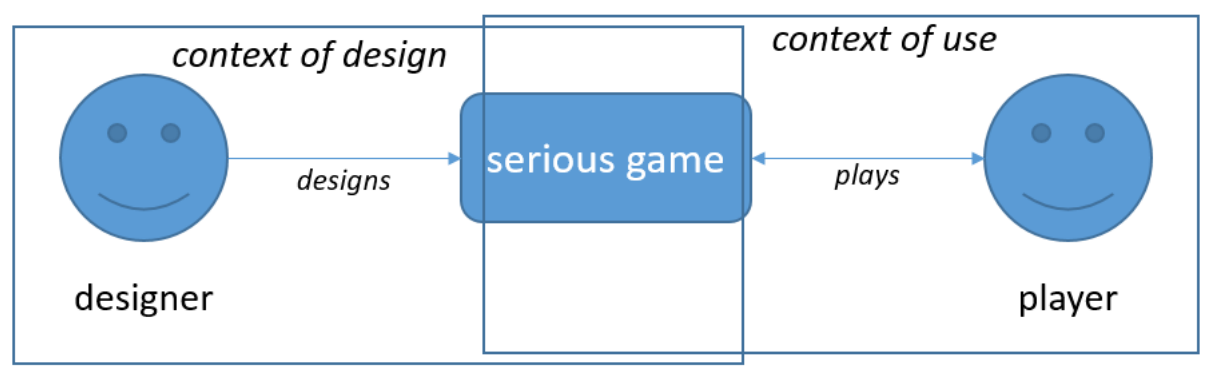

Fig. 1. The context of design and the context of use in serious games.

In the design of artefacts such as serious games, it is important to consider the situation in which the artefact is meant to be used: in many cases, the design also necessarily encompasses aspects of the context of use [5]. For example, when playing a game in the classroom is embedded between an introductory briefing and a concluding debriefing, the design of the game itself, as well as the design of the surrounding activities, are of interest. Klabbers [6] refers to this as design-in-the-small (DIS) and design-inthe-large (DIL). Here, design-in-the-small refers to the game or simulation being designed as a digital artefact in itself, whereas design-in-the-large refers to changing the existing situation and embedding the artefact in its context of use. In serious games, the term game-based learning addresses this inclusion of the larger context of use as part of the design [7].

The use of computer games in a classroom is one example of embedding serious games in a particular context, and while it may be easy to bring a game into the class and play it, it is no silver bullet for education if the context is not adapted to accommodate the game $[8,9]$. The experiences of both teachers and researchers in embedding serious games into a curriculum have provided useful insights for how the class context can be adapted [10], arguing for a focus on the underlying concepts and ideas behind the learning activities, of which playing games may be one example. Specific examples of tuning the context to improve the effectiveness of a serious game can be found when addressing higher-order cognitive learning and attitudinal or affective goals. The reflection step in learning can be accommodated by organizing a debriefing to make sense of the experience of play [11] and metacognition may be improved by discussing play in groups [12]. Thus, the design of serious games may extend beyond the design of the game itself: often other interventions in the context of use are required as well. 


\subsection{Differences in Audience and Purpose}

Serious games are being proposed, designed, built, and evaluated across an increasingly wide range of application domains. An early serious games taxonomy distinguishes between seven domains, ranging from government, education and health care through to marketing, defense and industry applications [13]. The same taxonomy loosely introduces a number of serious games categories, such as games for health, games for training and games for work. More recently, a classification scheme that distinguishes between gameplay, purpose, and scope of serious games has been proposed [14] to classify serious games. Of this latter G/P/S-model, the dimension of scope addresses two of the most salient areas from which design requirements stem: the intended audience and intended purpose of the game.

The audience targeted by a serious game is an important source of design requirements: gameplay, look-and-feel and suitable technology need to be in tune with the future players. Traditionally, games are often associated with kids and henceforth many serious games target children before, in, or after primary school. However, more recently much attention has been given to so-called silver gaming: using serious games to improve the quality of life of the elderly [15]. While the games targeting the younger audience often have an education-related goal, games targeting the elderly often have health-related goals such as promoting regular exercise or improving cognitive function. Although other target audiences, such as adolescents in specific work situations or students in higher education, have seen less attention, the notion that the average age of gamers is rising has led to increasing attention for different ages in recent years. Some serious games focus on very specific audiences with specific design requirements, such as children with autism-spectrum disorders [16] or visually impaired persons $[17,18]$.

The purpose targeted by a serious game is another important source of design requirements: gameplay and other content and interactions within the game need to support the overarching purpose of the game. One of the most outstanding uses is for education and training, leading to the term educational games. In this case, the purpose of the game is to help a learner achieve a given set of learning goals by playing the game. However, the content and activities afforded by the games may differ widely: some provide training and instruction as well as performance assessment, others are limited to repeated practice with automated feedback (skill drill). Another well-known purpose of serious games is to stimulate exercise, leading to the derived term exergame. In this case, the game is designed to let the player perform certain behaviors by providing them with engaging game mechanics [19]. While some exergames have the behavior itself as the main goal, other games strive to increase a user's self-efficacy to maintain this behavior over longer periods [20] or try to generate enough content to keep a user motivated over a longer period of time [21]. Where exergames normally address behavior change in individuals, one final well-known application of serious games is to elicit social change and attitude change, leading to the terms games for change [22] and persuasive games [23]. Outside this scope falls a category of games used to support research itself by gathering data or exploring a solution space. A typical example is FoldIt, which crowdsources possible protein folding solutions through gameplay [24]. 
Table 1. Subdivision of learning goals into cognitive, skill-based and affective outcomes [25].

\begin{tabular}{|c|c|c|}
\hline \multicolumn{3}{|c|}{ Learning Outcomes } \\
\hline Cognitive & Skill-Based & Affective \\
\hline $\begin{array}{ll}- & \text { Verbal knowledge } \\
- & \text { Knowledge organization } \\
- & \text { Cognitive strategies }\end{array}$ & $\begin{array}{ll}- & \text { Compilation } \\
& \circ \text { proceduralization } \\
& \text { c composition } \\
\text { - } & \text { Automaticy }\end{array}$ & $\begin{array}{ll}- & \text { Attitudinal } \\
- & \text { Motivational } \\
& \circ \text { motivational disposition } \\
& \circ \text { self-efficacy } \\
& \circ \text { goal setting }\end{array}$ \\
\hline
\end{tabular}

The wide range of purposes of serious games, target audiences addressed by serious games, and ways of embedding serious content into a serious game, makes it complicated to discuss the design of serious games in general: in almost all cases the specific area of application or the specific goals of the game need to be taken into account. The classification of learning outcomes distinguishes between cognitive, skill-based and affective learning outcomes [25], and provides a suitable framework to address the different goals we find in serious games. For cognitive outcomes, a further subdivision into verbal knowledge, knowledge organization, and cognitive strategies is made, which can be related to many educational games. For skill-based outcomes, the focus is on maintaining the skills through compilation and automaticity, which can be related to many exergames. For affective outcomes, attitudinal goals may be set, relating closely to persuasive games. Additionally, the affective outcomes include motivation, and links this with motivational disposition, goal-setting, and self-efficacy, providing a basis for the motivational aspect in many serious games (see Table 1). With these notions, in the following serious games are discussed from this broader perspective of addressing particular types of learning outcomes.

\subsection{Differences Between Entertainment Games and Serious Games}

Whereas games for entertainment are probably best known by the general audience of consumers, serious games are more known for being used in specific contexts and for specific audiences. This trait has two side effects. First, as the target audience is more specific and hence less in numbers, in general budgets or return-on-investment may be lower. Second, this has the consequence that the business-to-consumer (B2C) model, prevalent in entertainment game market, is nearly absent in serious games. Rather, a business-to-business (B2B) model, often combined with subsidized consortia of business and academic partners, is seen more often.

However, certain serious game projects seem to succeed in combining a solid business case with an academic underpinning. Quest Atlantis has had the benefit of having a long development time, a good budget and consecutive revisions [26]. Moreover, it was received well and discussed in various published articles [27,28,29]. Other games appear to completely cross over the entertainment/serious games boundary: America's Army is used in army training courses, but also played for entertainment. For a further 
discussion of differences between entertainment and serious games, and alternative classifications, see [14].

\subsection{Conclusions}

In this section we have identified a number of contextual aspects that influence the design and development of serious games. In particular, the distinction between the context of design and the context of use provides insight into the considerations for the designer. Identifying and taking into account the requirements that stem from these aspects improves the suitability of the design for the selected purpose and audience.

\section{$3 \quad$ Processes}

In the previous section we have seen a wide range of aspects to consider in the design and development of serious games. Therefore, it is not straightforward how to approach such a complex task: the effects of many design choices are uncertain under different conditions and even more so in conjunction with other design choices. To remedy this complexity, various frameworks that describe design and development processes have been proposed, and in this chapter we will discuss a number of them.

According to Khaled \& Ingram [30], there are at least five active perspectives within serious game projects in general: project organization, technology, domain knowledge, user research, and game design. In this section we will focus on the processes used for organizing the design and development process, and how to integrate domain knowledge and user information through the use of research and user-centered design methods. Aspects pertaining to the specific game design choices will be discussed in the next section on models.

\subsection{Including Phases and Iteration}

The design and development of serious games includes various phases with different purposes: there is a difference between designing (producing a concept) and developing (producing a product). The ADDIE-model is an often-used high-level organization of the design and development process, distinguishing between phases of analysis, design, development, implementation (in the context of use), and evaluation [31]. Additionally, it supports an iterative approach where results from a previous evaluation feed into the 
analysis and design phases of the next iteration and hence incrementally improves the design and/or the product (see Fig. 2).

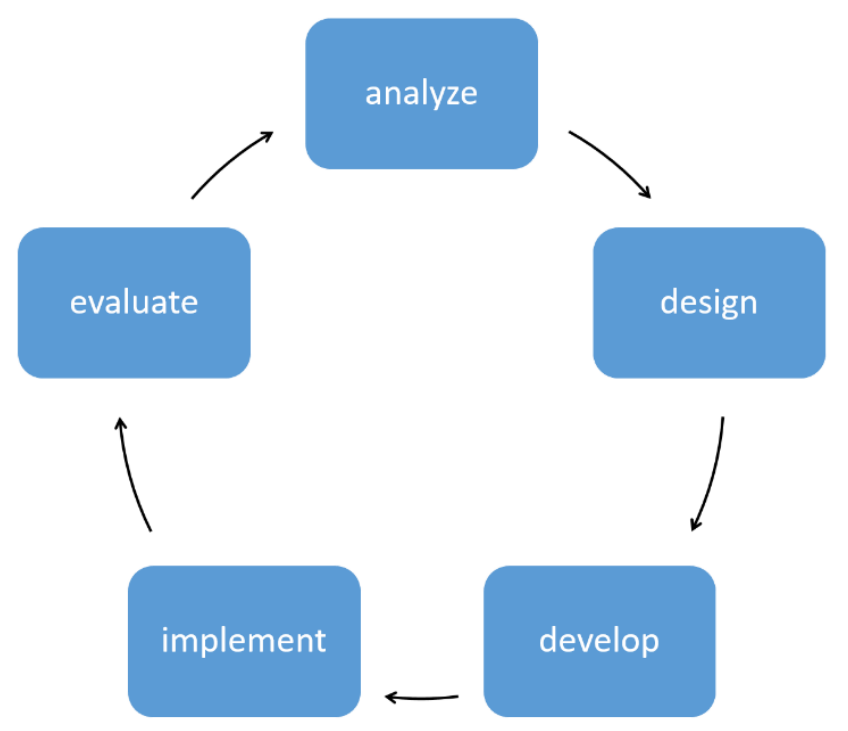

Fig. 2. A visualization of the cyclic ADDIE process.

This cyclic and phasic approach underlies various other existing approach to serious game design. In an attempt to reduce design complexity, and hence development costs, the EMERGO-toolkit and associated approach are based on the ADDIE-cycle [32] and focus on how to address case requirements in the design. Similarly, but focusing on the evaluation phase instead, the ADDIE-cycle underlies an approach to improve usability, playability, and learnability in games [33].

In practice, this cyclic approach is often supported by a software development methodology known as Scrum (see for example [34]). This emphasizes incremental development and evaluation of prototypes during the development process and integrates well with the ADDIE-approach. The use of Scrum has seen significant rise in recent years, particularly in the field of game development.

\subsection{Including Research}

General consensus is that research has a definite and prerequisite role in the design and development of serious games. In particular domain-specific analysis as part of the design, and effectiveness studies as part of the evaluation or validation, are commonplace. However, how to combine research throughout the design and development process is less clear.

The goals of transfer of the learning content beyond playing the game call for a design that can be underpinned by theory from relevant fields, as well as known best practices, and often an evaluation or validation study is included to assess to what extent 
the design meets its objectives. However, a game and its underlying design cannot be studied in isolation; the context in which it is employed and played has an influence on the results obtained [35]. Consequently, many researchers argue for adopting an approach that integrates design and research to design and analyze serious games: designbased research [36]. At the same time, the from the field of education, similar calls for applying design-based research approaches for studying educational interventions are being proposed $[37,38]$.

The design of serious games is concerned with ensuring a solid embedding in existing literature and best practices, while also addressing the specific demands of the domain of application. While this domain of application may require more detailed and domain-specific models, the three-cycle model of design science [39] provides an overarching view for designed artefacts in general and information systems in specific [40]. This model describes three cycles that operate to link design, research, and practice together. Through the relevance cycle, problems from practice can be taken up into a design process while produced artefacts, such as serious games, can be evaluated in practice to make sure that they contribute to solving the problems. Through the knowledge or rigor cycle, artefacts and theories from current knowledge can be taken up in the design process to base new solutions on existing work, while results from this research can be added to the knowledge base (see Fig. 3). The design cycle, then, is at the heart of the design process and refers to an iterative approach to design and developing the artefacts.

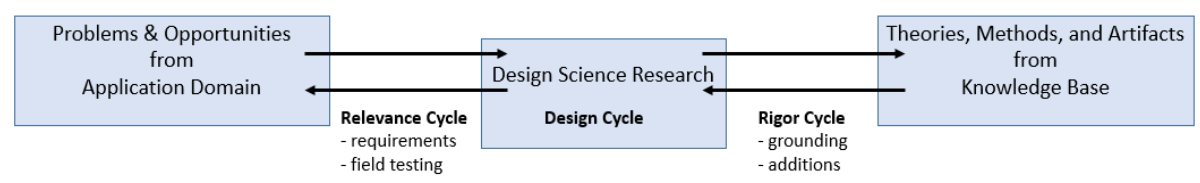

Fig. 3. A three-cycle view of design science research [39].

Focusing prominently on the research and evaluation aspects, Mayer and colleagues [41] argue for a more coherent approach to research, and offer concrete advice on the development of a corresponding research framework. They specifically aim to address the broad application scope of serious games, while being useable in practice. They define further comparative analysis of serious games, improving evaluation constructs and scales, and digital tooling integrated into games as the next steps forward. While this seems like a promising direction, an overarching and game-specific research framework is still lacking.

\subsection{Including Users}

As discussed earlier, there is wide support in literature and practice for a user-centered design methodology in designing and developing serious games: in an attempt to bridge the designer-player dichotomy, it is paramount to involve members of the target audience in the design process. In recognition of the need for specific design frameworks, Rankin, McNeal \& Gooch [42] describe how they used a user-centered design 
approach for evaluating second language acquisition in existing games. In this model of user-centered game design, phases such as conceptualization, prototyping, and playtesting can be distinguished and are explicitly associated with user-focused research steps and outcomes. As they use existing entertainment games such as EverQuest II to embed learning scenarios, this is also an example of repurposing: using the game for a purpose it was not originally designed for.

The role of the user in the design process may differ: sometimes, like in the previous model, the user input is gathered through focus groups and evaluations. In other cases, the user takes on a more active role and actually actively contributes to the design [43]. In the latter case, we label this as participatory design, rather than just user-centered design.

Including users in the design process is particularly hard when there is not yet a playable version of the game. The observation that it is hard to address design problems in a concept before it is developed into a playable game is widely recognized [44]. In order to gather the feedback from playing with users as early as possible, an iterative approach that creates early prototypes of the game is preferable - such a player-centric approach is fully outlined in the book entitled Game Design Workshop by Fullerton [45]. As digital prototypes require more effort to construct and change, often paper prototyping is used in early iterations: using physical papers, cards, die, pawns, and such to simulate future gameplay early on.

Whereas physically prototyping digital games definitely has its place in the design process, there limitations in representing for example real-time action components [46]. To make the transition from written design document to playable prototype easier, several authors have noticed a lack of design vocabulary and argued for more formalized ways of defining game designs in terms of their mechanics $[47,48,49]$. The introduction of so-called game design patterns [50] can be viewed as another effort to capture the effects and interactions of different game design choices, and will be explored for serious games later in this chapter. This formalization approach has been further elaborated in the Machinations framework [51], which combines a model-based theoretical perspective with digital tools to allow designers to alter design choices and see their effects in practice.

Taking the previous perspectives into account, we will use the ADDIE phases of analysis and design, and then those of development and evaluation to discuss a number of existing frameworks.

\subsection{Analysis \& Design}

The coming together of different disciplines, particularly game design and instructional design, is one of the main topics in designing educational games. In an effort to combine pedagogy and play, as well as retaining fidelity to the subject matter, Rooney proposes a triadic framework that integrates these aspects [52]. She addresses different learning methodologies, such as situated learning and experiential learning, as part of this framework and further argues for theoretical underpinnings of designing games within these contexts. A conceptual approach that identifies similar dimensions of Game vs. Learning, Game vs. User, and User vs. Learning addresses further details of 
designing and analyzing educational games [53]. Another approach aimed at integrating didactic and game design perspectives focuses specifically on the iterative nature, as addressed in the previous section. In this approach, the authors emphasize the didactic perspective throughout the various phases of the design process [54].

Such a theory-based design approach was used in the design and development of a serious game to reduce cognitive biases [55]. In this study, an explicit link between the domain knowledge of cognitive biases to the game mechanics and in-game narrative is made, and subsequently evaluated the game with users to test for effect and efficacy. When the domain knowledge is not present in the designers or the researchers involved, integrating domain knowledge into the game becomes more complicated and may require active consideration as to how to involve the experts [56]. The integration of serious content within the mechanics, balancing fun and education, is a widely debated topic and even practitioners have varying methods and processes for approaching this problem [57], which only further emphasizes a key problem in serious game design: a common framework for the effective design of serious games is lacking [58].

\subsection{Development \& Evaluation}

The phases of development and evaluation have similar complexities that influence the effectiveness of the game. For example, in the development of a science education game, the authors/researchers worked together with a number of different roles: domain experts in biology, immunology, experts in pedagogy and learning science, and game designers [59]. They did face a number of design choices where the game designers had different ideas from the educational experts, for example when interspersing the gameplay with the option to ask questions. The team overestimated the features that could be implemented and underestimated available time, ending up having to cut a number of design aspects, such as a full 3D simulation or soft-body physics.

In order to assess the qualitative and/or quantitative results found through evaluation of a game, an interpretation of what the results mean must be made. This includes tracing back the effects found to specific elements in the design of the game. One method is to underpin design decisions from theory and trace them to the evaluation phase [60], allowing the subsequent iteration to be informed by previous choices. Another, more formalized and labor-intensive method, is to code specific game stimuli and responses and assess these during evaluation [61]. This latter approach was shown to work within the setting of an exergame, making it highly relevant to include physical responses in the evaluation.

There are many different approaches, methodologies, and techniques to gather data for the evaluation of games. They range from physiological measurements, such as facial muscle activity (via EMG) or heart beat intervals, to audio/visual technologies, such as video and online or retrospective talk-a-loud protocols, to in-game assessments, such as route logging and game analytics [62].

Some evaluation frameworks specifically address the aforementioned player context, player background and application to serious games [63]. When the evaluation is specifically focused on the player experience or gameplay experience, specific evaluation methods such as the Gameplay Experience Questionnaire (GEQ) [64] may be used. 
More often, a combination of methods is used, such as combining observations and self-reports. For example, in a study after game design for the elderly, the GEQ was combined with qualitative observations [65]. Adaptations to make the GEQ suitable for serious games are being researched, but have thus far concluded that the variation in context of playing had large impact on the results obtained, finding that the various design stages did improve usability but not gameplay experience [66].

A typical example of the evaluation of serious game is found in the comparison of an educational game to traditional instructional methods in teaching computer programming [67]. This evaluation addresses the effectiveness of both the game design and the learning. Tying into the design-based research approach discussed earlier, specific assessment frameworks for games and simulations have been developed [36]. Specifically for serious games, a step-based approach that integrates usability and playability into the process is described by Olsen et al. [33]. Other scholars focus on online or ingame evaluation, by developing learning analytics systems as an integrated part of educational game design $[68,69]$. This approach stretches beyond the design process: it also provides end-users such as learners and teachers with insights into the performance of both the learners and the game itself.

\subsection{Integrated Process Frameworks}

Considering all the aspects of context, process, involving users, and embedding research, creating an encompassing process that supports most serious games projects is complex. Moreover, a process framework must be academically sound as well as feasible for use in practice. Notwithstanding these challenges, a number of such integrated frameworks have been put forward and further elaborated upon.

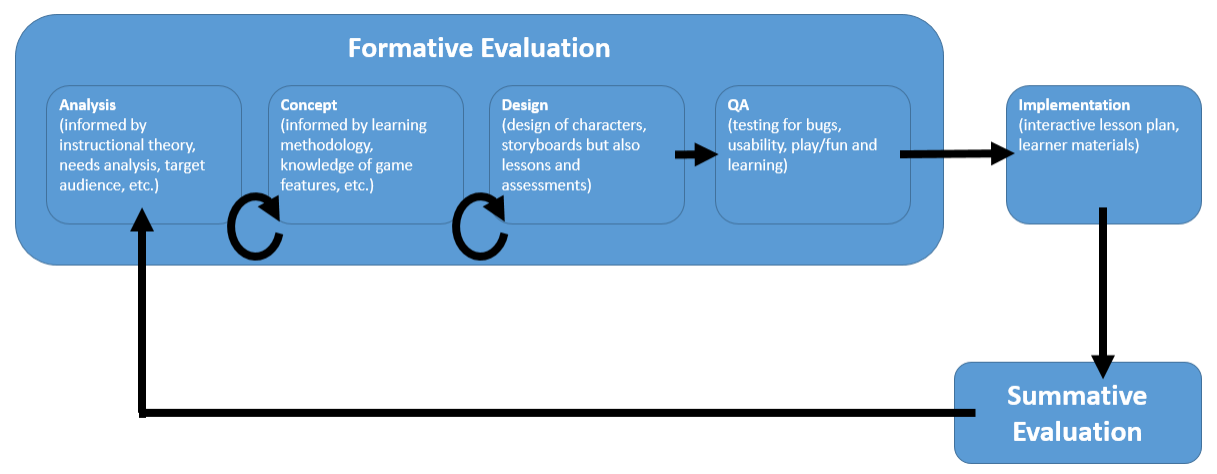

Fig. 4. The integration of design-based research with game development phases in the Simulation-game Instructional Systems Design Model [70].

An approach of combining design-based research, information system design, has been further adapted for serious games into the Simulation-game Instructional Systems Design (SG-ISD) Model [70], by paralleling game development phases from the tradi- 
tional Waterfall-model of software engineering with information systems design methods based on the iterative ADDIE-model (see Fig. 4). In the analysis phase, they emphasize the integration of instructional theory into the game design, and in the design phase learning methodology and game features need to be integrated. This design framework provides further guidelines for testing (formative evaluation), prototyping and playtesting and evaluation in practice (summative evaluation). Later, they extensively discussed the use of the model in practice [71]. While this framework is intended specifically for the design and development of educational simulation games, it includes many of the features discussed earlier, and hence seems like a good step towards a more general-purpose process framework.

In the absence of process frameworks that address the design and development of serious games across the broad range of application areas, several authors have proposed specific, instantiated frameworks for particular areas of serious games. Focusing specifically on educational adventure games, an early effort to define a coherent design approach is found in the work of Moser [72]. In this approach the ADDIE model is iteratively expanded with specific adventure game design choices such as which characters, what puzzles, and what user interface to include.

In an effort to reduce the design complexity involved in addressing increasingly complex learning outcomes, a study that focuses on scenario-based games has provided a framework that links conceptual design aspects with an underlying technical architecture [32]. In this model, the game itself is embedded within a larger game-based learning framework that includes supportive views for both learners and teachers, as well as analytics and monitoring of learning integrated in the game world. Two alternate approaches and examples of applications of such models can be found in collaborative decision making games [26], and games for cultural heritage [73].

In an attempt to standardize development approaches for particular user group, and improving consistent game design, evaluation, and efficacy, the game-based learning development approach was proposed [74]. This approach distinguishes between three perspectives on the design and development process. At the process level, the project runs from a case through the ADDIE-phases, towards a designed learning activity. At the principles level, a number of guidelines for learning with games are emphasized, such as fostering positive attitudes and using game-based learning only when appropriate. At the tools \& techniques level, these phases and principles are aligned with particular practices, such as questionnaires, prototype evaluation and trials.

While an iterative approach is hinted upon with the arrow extending from evaluation at the process level, the other levels do not support a similar iteration. Moreover, including stakeholders and users only in later phases is at odds with most user-centered design practices.

\subsection{Conclusions}

In this section we have identified a number of requirements for a process framework that supports the design and development of serious games. Such a framework must support different phases such as analysis, design, development, and evaluation, in an 
iterative fashion. Furthermore, such a framework must facilitate the integration of domain knowledge and support the evaluation of effects achieved through playing the game. User-centered design seems like an appropriate framework to draw upon, as it emphasizes including the user within the process - either passively (focus groups) or actively (participatory design). While integrated design and development frameworks are emerging, currently each framework is suitable only for a specific set of serious games and a general design and development framework is lacking.

\section{$4 \quad$ Models}

In the first part of this chapter we have presented a number of ways to approach the design and development of a serious game. The focus has been on the overarching process: which steps to take and how to evaluate whether these steps are working out towards a final product. However, this leaves unaddressed the question of how to make the right design choices in the design of the game itself. This section discusses a number of models that attempt to describe what choices in setting, mechanics, and gameplay have what kind of effects on the motivation and learning of the user.

When designing a serious game, the designers must consider both the learning goals that the user needs to achieve and the motivational factors that help the user to continue playing. Some models for serious game design emphasize either the learning or the motivational characteristics of games, whereas other models try to integrate both aspects more coherently. We will first discuss some of the main motivation-focused models and learning-focused models and then present some of the integrated models.

\subsection{Motivation}

One of the first studies to systematically explore what makes computer games fun, and how to use their features for learning identifies a number of motivational factors in games [75,76]. A number of games were modified, compared, and evaluated to identify the motivational elements of challenge, fantasy, and curiosity. Challenge seems to relate to intrinsic motivation when it meets particular standards - for example a balance between player ability and game difficulty. Fantasy refers to the representational part of games, regardless of whether the depiction is realistic or non-realistic; fantasy here is used to set it apart from an abstract game. Curiosity refers to the uncovering of feedback and auditory and visual aspects.

Whereas the previous study analyzed games to identify design principles, others have taken the approach of using motivational theories to explain how players are engaged by games. In one such study, self-determination theory [77] was used to analyze motivation in games from a perspective of a player satisfying their needs. In singleplayer games, perceived competence and autonomy were shown to indeed explain game enjoyment and preference for future play, whereas in multiplayer games the aspect of relatedness served the same role [78]. Later on, this approach was extended to include explanations for short-term well-being, the appeal of in-game violence, and post-play aggressive behavior as well [79]. 
Acknowledging that research literature was lacking clear principles on how to engage users with particular game features, while achieving the desired instructional goals, Garris, Ahlers, and Driskell have put forward a research-and-practice model [80]. This model identifies key game features and types of learning outcomes, and links these to a game cycle of user judgments, behavior, and feedback that supports learning. This input/output-model emphasizes the integration of instructional content and game characteristics to help achieve the learning outcomes in the player. Based on existing studies, this model also expands the aforementioned game features challenge, fantasy, and curiosity with rules, goals, and control, and tries to link them with learning outcomes in the skill-based, cognitive, and affective categories [25]. The authors, however, stress that while games offer the instructional opportunities to learn by doing, not everyone learns by doing and not everything can be learnt by doing.

\subsection{Learning}

With the increasing attention for serious games, the need for using sound educational principles to design them also increased: motivational and educational effectiveness needed to be integrated into the serious game design process [81]. By combining existing pedagogical models, such as the ARCS model of attention, relevance, confidence, and satisfaction [82], Gagné's nine events of instruction [83], with a number of common game elements, the RETAIN-model defines a three-level motivational model of games: relevance, embedding of the learning content, transfer, adaptation to the player, immersion, and naturalization of the learning goals [84]. This can be seen as a model that can be used both to analyze and design serious games using these principles. A similar approach compares four lenses (motivation, flow, learning environment, and gameplay) to a number of common game elements (interest, goals, challenge, and feedback) in a comparison [85]. This comparison shows that key features of games are in line with factors promoting motivation and learning (see Table 2).

The models discussed so far have taken motivation as the main emphasis, but necessarily identified learning as one of the other required serious game components. Other models have completely focused on how learning can take place through games and how existing and new pedagogical models can help to understand and improve the effectiveness of serious games. Taking learning-by-doing or experiential learning as a starting point, the experiential gaming model [86] links the four stages of experiential learning [87] to particular game activities and features. Specific emphasis is placed on storytelling, game balance, and optimizing cognitive load, in order to improve effectiveness of learning and as such this model emphasizes learning through the core mechanics and the design of the game.

Another route to approach the problem of designing effective serious games is by taking the intended learning outcomes as a start point. This directly raises the questions of which game activities are best suited to help a learner achieve those outcomes. The Game Object Model [88] tries to identify elements and objects within game design and creates a taxonomy of these elements as a design tool. The learning mechanic/game mechanic, or LM-GM model [89] then tries to match particular learning mechanics to particular game activities. Similar approaches of aligning gameplay with learning exist 
[90,91]. These can be viewed steps towards finding a relation between the design aspects of a game and the effects and effectiveness of that game as a tool for learning.

Table 2. Similarities between game features and factors promoting motivation and learning [85].

\begin{tabular}{|c|c|c|c|c|}
\hline & Motivation & Flow & $\begin{array}{l}\text { Learning } \\
\text { Environments }\end{array}$ & $\begin{array}{l}\text { Game Design/ } \\
\text { Play }\end{array}$ \\
\hline $\begin{array}{l}\text { Focus/ } \\
\text { Interest }\end{array}$ & $\begin{array}{l}\text { Attention strate- } \\
\text { gies for arousing } \\
\text { and sustaining cu- } \\
\text { riosity and interest. }\end{array}$ & $\begin{array}{l}\text { Attention is com- } \\
\text { pletely absorbed in } \\
\text { the activity. }\end{array}$ & $\begin{array}{l}\text { Avoid distractions } \\
\text { and disruptions } \\
\text { that intervene and } \\
\text { destroy the subjec- } \\
\text { tive experience. }\end{array}$ & $\begin{array}{l}\text { Sensory and cogni- } \\
\text { tive curiosity } \\
\text { within the learner. }\end{array}$ \\
\hline Goals & $\begin{array}{l}\text { Relevance strate- } \\
\text { gies that link to } \\
\text { learner's needs, in- } \\
\text { terests, and mo- } \\
\text { tives. }\end{array}$ & $\begin{array}{l}\text { The activity has } \\
\text { clear goals. }\end{array}$ & $\begin{array}{l}\text { Have specific } \\
\text { goals and estab- } \\
\text { lished procedures. }\end{array}$ & $\begin{array}{l}\text { Goal reaching and } \\
\text { feedback. }\end{array}$ \\
\hline Challenge & $\begin{array}{l}\text { Confidence strate- } \\
\text { gies that help stu- } \\
\text { dents develop a } \\
\text { positive expecta- } \\
\text { tion for successful } \\
\text { achievement. }\end{array}$ & $\begin{array}{l}\text { Challenge is opti- } \\
\text { mized. }\end{array}$ & $\begin{array}{l}\text { Provide a continual } \\
\text { feeling of chal- } \\
\text { lenge that is neither } \\
\text { so difficult as to } \\
\text { create a sense of } \\
\text { hopelessness and } \\
\text { frustration, nor so } \\
\text { easy as to produce } \\
\text { boredom. }\end{array}$ & $\begin{array}{l}\text { The learner should } \\
\text { continually feel } \\
\text { challenged as diffi- } \\
\text { culty increases in } \\
\text { concordance to in- } \\
\text { creased skills. }\end{array}$ \\
\hline Feedback & $\begin{array}{l}\text { Satisfaction strate- } \\
\text { gies that provide } \\
\text { extrinsic and in- } \\
\text { trinsic reinforce- } \\
\text { ment for effort. }\end{array}$ & $\begin{array}{l}\text { The activity pro- } \\
\text { vides clear and } \\
\text { consistent feed- } \\
\text { back as to whether } \\
\text { one is reaching the } \\
\text { goals. }\end{array}$ & $\begin{array}{l}\text { Provide a high in- } \\
\text { tensity of interac- } \\
\text { tion and feedback. }\end{array}$ & $\begin{array}{l}\text { The learner should } \\
\text { feel a sense of con- } \\
\text { trol through endog- } \\
\text { enous feedback } \\
\text { provided by the } \\
\text { game. }\end{array}$ \\
\hline
\end{tabular}

\subsection{Integration and Alignment}

In the previous discussion we have seen that the models for designing serious games have incorporated aspects such as motivation and the learning objectives. This leaves the question of how to integrate these in an effective manner unanswered. In an experiment comparing intrinsic embedding of the learning content with the gameplay to an extrinsic embedding, Habgood et al. found an increased motivation for the activities [92]. The integration of learning with gameplay, and hence the alignment of gameplay activities with learning activities, is a topic of ongoing research.

Where the LM-GM model focus specifically on the design of the game, the motivation and goals of the user playing the game must also be considered as part of the design space. Drawing from activity theory, Carvalho et al. [93] have put forward a multi- 
layered model that extends the LM-GM-model by addressing different motives and contexts. This model distinguishes between actions and motives outside of and inside of the game, as well as aspects of the context of use, such as community, rules, and culture. For the design of serious games, this model is a recent and comprehensive basis to link design decisions to intended effects from an integrated perspective.

In the context of evaluating existing serious games, a four-dimensional framework that takes into account learner specifics, pedagogic considerations, mode of representation, and context of use is proposed [94]. This work is further expanded upon by distinguishing between the learning question, the instruction question, the assessment question, and the alignment question and then incorporating a number of the previous approaches into an integrated model [95].

In this game-based learning framework, the motivational aspects and the learning cycle of user engagement, user learning, user behavior and player feedback are made explicit, as well as the integration of learning objectives and content. However, a further specification of the game elements or mechanics to include, and to what effect, is omitted. It seems that a further elaboration on serious game design and evaluation models is still required in order to support integrated design with an integrated framework.

These latter and more recent examples show a currently emerging approach in serious game design: that of aligning the gameplay with the goals of the game at different levels [96]. A more recent and further analysis of promises and challenges in aligning gameplay content with learning goals has led to a number of principles for achieving this match [91], such as making mental models of what the player needs to learn, and supporting strategic thinking and cognitive skills by teaching more than just the content itself.

\subsection{Conclusions}

In this section we have discussed a number of models that assist in making design choices as part of an overarching design and development processes. Whereas earlier models focused on motivational aspects, more recently the emphasis has come to lie on the alignment of gameplay activities and the goals of the game. This approach of integrating learning and playing, and linking specific design choices to specific effects, seems like a promising next step in serious game design research.

\section{$5 \quad$ Serious Game Design Patterns}

As mentioned, a major challenge for the designers of serious games is to create an engaging gameplay that is also effective in achieving desired purpose. If serious games are designed only by game designers, they may be entertaining but may lack the effect of primary purpose; if they are designed by teachers and trainers, they might be very efficient, but lack the motivational appeal [97], which is one of the key reasons to use serious games in the first place [98]. Therefore, in order to address this issue, stakeholders from the "serious" side and "game" side should cooperate in the design process. 
However, lack of a shared design vocabulary and tool box containing both broad application solutions and solutions specific to certain genres of games is a major issue and limitation [99], even though such shared and unified vocabulary can bring significant benefits to the area [100]; this was pointed out already in the past by several authors such as Costikyan and Church $[47,48]$. Serious game design patterns seem to be a promising approach and solution to address this challenge and to facilitate collaboration, cooperation and mutual understanding between different stakeholders [101].

\subsection{What Are Game Design Patterns?}

A design pattern is a general reusable solution to a commonly occurring problem after it has been successfully applied in specific contexts in response to specific design problems, such as learning in the affective domain [102]. As a method patterns were first introduced in architecture by Alexander: "Each pattern describes a problem which occurs over and over again in our environment, and then describes the core of a solution to that problem, in such a way that you can use this solution a million times over, without ever doing it the same way twice" [103].

Later, Gamma et al. introduced the use of design patterns in software engineering [104], however, design patterns are today used in various fields such as, for example, human-computer interaction and interaction design [105]. In education they are applied in active learning, management systems and intelligent tutoring systems [97]. Nonetheless, none of these uses takes in account the game-playing dimension [97].

In game design, the use of patterns was introduced by Kreimeier [106] and put forward by Björk et al. [107]. Unlike in software engineering where patterns provide strict solutions, game design patterns should not be seen as such as game design is a creative process which often does not have one right solution [107]. Important to note is that game design patterns are used for an earlier stage than actual application development [108]. In this regard, the game design pattern description itself is just a summary of causes and effects, describing one way to reach a given objective [106].

There have been various approaches in researching and documenting game design patterns. Currently, the most significant attempt to set up a database of design concepts is Björk and Holopainen's collection of more than 200 design patterns [99] and it is also considered as most coherent and functional [97]. Their structure of the pattern can be seen as an evolution over the Formal Abstract Design Tools (FADT) suggested by Church and consists of 1) name, 2) concise description, often with notes in which game the pattern was identified, 3) consequences of applying the solution suggested by pattern, 4) how to use the pattern, and 5) relations to other patterns [107]. Moreover, it should be mentioned, that some researchers used the proposed pattern structure also as basis in formalising and expanding serious game design patterns, linking it with the "serious" part of the game $[108,109,110,111]$. Kelle, for example, introduced the concept of "game learning patterns" (GLP) as a methodology for the design of learning games by using game design patterns and matching these with corresponding learning functions [108] while Reuter et. al researched design patterns for collaborative player interactions [110]. 


\subsection{Why Use Patterns for Serious Games Design?}

Game design patterns create a shared design vocabulary and can be used for problem-solving during development, idea generation, as creative design tool, to communicate with peers and with other professions [105], for analysis and categorization of games, for exploration of new mediums and platforms [107], such as, for example, mixed reality games [112]. In this regard, game design patterns become even more useful not only for analysis but further extend themselves into areas like authoring, content, software development and testing as these games introduce new design aspects compared to traditional videogames (e.g. reliance on inaccurate sensor data, close coupling to the real world context they are played in) [112]. Furthermore, recently, Dahlskog et al. identified a set of patterns at different sizes and levels of abstractions (micro-, meso- and macro-) for procedural content generation which also further strengthens the link between game design patterns and software development [113].

The usability and advantages of design patterns have also been recognized in the serious games community [101]. Dormann et al. proposed using game patterns as a conceptual tool to initiate discussions about the role of affect in games and to support the design of games situated in the affective domain [102]. In their research, they used game patterns to "bridge the gap between theories and high-level affective principles to their representation or actualization through games" [102]. Thus, developing a collection of game patterns helped gaining insights into the design of affective learning in games and raised a number of issues to take into consideration [102]. Moreover, Mader et al. argue that patterns help to better understand features that make play engaging and motivating which helps maximize patients' intrinsic motivation and smooth out the medical aspect of therapeutic games, consequently making a serious game more effective for treatment or therapy [114]. Not engaging gameplay was also a common critique of games designed to address brain injury rehabilitation and patterns might be a solution [109]. Moreover, Cheng et al. argue that investigating patterns in games for rehabilitation is beneficial for researchers and designers for several reasons: 1) game design patterns have the capacity to capture the qualitative information about brain injury rehabilitation, 2) have the ability to distill abstract game design knowledge from a large amount of data about how well existing games worked in therapy into a set of coherent and tangible exemplars, and 3) patterns as a common language can serve as a valuable tool to facilitate effective communication and mutual understanding among game designers and therapists [109].

In this regard, as patterns are a formal means of documentation [106], we can argue that they are key enablers for structured research in the serious game domain. Game design patterns seem to be a promising choice as they provide a means of capturing existing successful design practices, expand knowledge about game design and provide a shared design vocabulary for communication between researchers, game designers, and developers [102]. In addition, lack of such procedures can slow down production of serious games and likely has a negative impact on the quality of the products as currently each project is more a new challenge than the re-use of established and wellgrounded procedures [101]. Research findings also suggest that design patterns help various stakeholder to faster acquire new knowledge that is outside their expertise. This 
is supported by an interesting observation from Marne et al. fieldwork research which showed that teachers were more interested in game related patterns while game designers were more interested in pedagogical patterns [97]. Moreover, findings also supports Björk et al. claims that game design patterns are beneficial to multidisciplinary groups as they ease communication [107].

Lastly, structured research can be supported with expanded documentation of game design patterns which also covers more in-depth "scientific part" with additional information such as for example ethical concerns, serious purpose, data gathered, etc. Serious games Design Pattern Canvas (DPC) (see Fig. 5) is such proposal towards unifying serious games design patterns with strong grounding in research. DPC is a visual chart with elements describing a pattern's purpose, mechanics, audience, consequences, collected data, related research, and ethical considerations [111]. The chart can be looked at from the center, where the left side is aimed at design questions ("serious" part) and the right side is dedicated to interaction design ("game" part). An example of such relevant and reusable information would be a research done in 2009 which demonstrated that the popular game Tetris is a visuospatial task that can reduce PTSD flashbacks if played after a traumatic event [115].

\begin{tabular}{|c|c|c|c|c|c|}
\hline \multicolumn{2}{|c|}{$\begin{array}{l}\text { Serious Game } \\
\text { Design Pattern Canvas }\end{array}$} & \multicolumn{2}{|c|}{ Name } & & \\
\hline \multirow{2}{*}{$\begin{array}{l}\text { Releated } \\
\text { Research, } \\
\text { References } \\
\text { Has the pattern been } \\
\text { used in any previous } \\
\text { research or serious } \\
\text { game? Has the pattern } \\
\text { been evaluated and } \\
\text { validated? A section } \\
\text { dedicated to validation } \\
\text { according to the } \\
\text { scientific method. }\end{array}$} & $\begin{array}{l}\text { Using the Pattern, } \\
\text { Related Patterns } \\
\text { When is it appropriate } \\
\text { to use the pattern? } \\
\text { How does the pattern } \\
\text { fit the bigger picture? }\end{array}$ & \multirow{2}{*}{\multicolumn{2}{|c|}{$\begin{array}{l}\text { Purpose } \\
\text { Why should we use } \\
\text { the pattern? For } \\
\text { serious games } \\
\text { purpose can be } \\
\text { defined as message- } \\
\text { broadcasting, } \\
\text { training or data } \\
\text { exchange [9] - should } \\
\text { be more specific for } \\
\text { patterns. }\end{array}$}} & $\begin{array}{l}\text { Mechanics, Task, } \\
\text { Gameplay, Rules } \\
\text { Rules, input methods, } \\
\text { Space/Time/Drama- } \\
\text { related setup. } \\
\text { Challenge and } \\
\text { variability should be } \\
\text { also considered. } \\
\end{array}$ & \multirow[t]{2}{*}{$\begin{array}{l}\text { Scope, Users, } \\
\text { Stakeholders } \\
\text { Who is our user? What } \\
\text { are they like? What are } \\
\text { their motivations? The } \\
\text { typical use of personas } \\
\text { can be implemented } \\
\text { here. }\end{array}$} \\
\hline & $\begin{array}{l}\text { Key Data } \\
\text { What data do we } \\
\text { gather? Do players } \\
\text { generate research } \\
\text { data? }\end{array}$ & & & $\begin{array}{l}\text { Media, } \\
\text { Biofeedback, } \\
\text { Channels } \\
\text { What channels does } \\
\text { the pattern use? Which } \\
\text { device? Is there any } \\
\text { biofeedback? }\end{array}$ & \\
\hline \multicolumn{3}{|c|}{$\begin{array}{l}\text { Ethics } \\
\text { Are there any ethical concerns? Are there any negative } \\
\text { effects in particular for serious game scenarios? How is } \\
\text { privacy handled? }\end{array}$} & \multicolumn{3}{|c|}{$\begin{array}{l}\text { Desired Outcomes, Consequences } \\
\text { This section should give emphasis on interaction results as } \\
\text { initially proposed in the game design pattern template by } \\
\text { Björk et al. [6]. }\end{array}$} \\
\hline
\end{tabular}

Fig. 5. Serious Game Design Pattern Canvas (alpha proposal) [111], inspired by the Business Model Canvas [116].

\subsection{Criticism of Patterns}

Most criticism of design patterns, such as considering them a fad and either too formal or not formal enough, comes from other fields, but can be also applied to game 
design patterns [105]. Still, these objections do not really criticize the notion of patterns, but rather the quality of their current conceptualization, use, and unspecified level of analysis they address; also, game design patterns are only useful as long they can be used and applied with reasonable effort to support development of a game or solve particular design problems [105].

In this regard Almeida \& Silva criticize game design patterns proposed by Björk et al. as not being enough documented, having contradictory documentation on patterns with disagreements between title, definition and usage examples while also lacking graphical models which together results in less intuitive use [99].

However, these objections do not really criticize the notion of patterns but rather the quality of their current conceptualization, use and unspecified level of analysis they address. Furthermore, it can be argued that with standardized design language and taxonomy the quality and usability of game design patterns could be improved. Nonetheless, as we can consider the game design patterns method still in its beginning, critiques like this should be addressed in future development of serious game design patterns. In addition, game design patterns need to be validated or it has to be at least specified in which development phase they are. As there is not much research on game design patterns validation, this can be considered as a major limitation and future research should also address this question.

\subsection{Conclusion}

To summarize, besides creating a shared vocabulary for various stakeholders, game design patterns have many benefits ranging from problem-solving during development, idea generation, as a creative design and communication tool for better collaboration with peers and other professions [105]. In addition, design patterns support analysis, categorization of games and exploration of new mediums and platforms are listed [107].

For the domain of serious games, we can argue that some of these advantages are even more beneficial. The documentation of design guidelines can assist in the knowledge transfer between generations of professionals [99] and different communities to a greater extent than before [105] which is a key factor for structured research built upon best and proven practices.

Lastly, design patterns provide means for structured evaluation and validation of serious games [114].

\section{Future Challenges}

Within the broader topics of this chapter, a number of future challenges or future research topics can be identified:

- How to integrate process frameworks with specific design models - thereby linking software development with creativity, pedagogical consideration, research and specific domain or field expert knowledge. 
- How to integrate pedagogy and instructional design with game activities and specific game aspects - thereby focusing not so much on if serious games can work but how to make specific designs work.

- How to form an accurate model of the end user throughout the design process and how to cater to this user - thereby focusing on adaptiveness of the game to the motivational and learning needs of the user.

- How to reap benefits from formalized approaches such as game design patterns, while leaving room for creativity and innovation.

\section{$7 \quad$ Further Reading}

A number of books can be suggested as further reading on the topics addressed in this chapter.

- Fullerton, T. (2014). Game Design Workshop: A Playcentric Approach to Creating Innovative Games. CRC Press. This book presents a pragmatic approach to creating games, emphasizing early (paper) prototyping, evaluation with players, and using the feedback obtained to improve the game iteratively.

- Kapp, K. M. (2012). The Gamification of Learning and Instruction: Game-Based Methods and Strategies for Training and Education. John Wiley \& Sons. This book brings together underlying theory and practical examples of using game design for learning.

- Schell, J. (2014). The Art of Game Design: A book of lenses. CRC Press. This book presents an extensive overview of game design theory through the use of a large number of different lenses to view to game through.

- Adams, E., \& Rollings, A. (2007). Game design and development. Person Education, Inc., Upper Saddle River, New Jersey. This book presents both game design theory and development approaches, detailing specific considerations for a wide number of established genres.

\section{Bibliography}

1. R. Hunicke, M. LeBlanc, and R. Zubek, "MDA: A Formal Approach to Game Design and Game Research," Work. Challenges Game AI, pp. 1-4, 2004.

2. M. Flanagan, H. Nissenbaum, D. C. Howe, and H. Nissenbaum, Embodying values in technology: Theory and practice. Cambridge University Press, 2008.

3. M. Flanagan and H. Nissenbaum, Values at Play in Digital Games. MIT Press, 2014.

4. A. Sandovar, "PhD Dissertation."

5. B. B. Marklund, "Out of Context - Understanding the Practicalities of Learning Games," in Proceedings of DiGRA 2014 Conference, 2014. 
6. J. H. G. Klabbers, “A framework for artifact assessment and theory testing," Simul. Gaming, vol. 37, pp. 155-173, 2006.

7. M. Pivec, O. Dziabenko, and I. Schinnerl, "Aspects of Game-Based Learning," in 3rd International Conference on Knowledge Management, Graz, Australia., 2003, pp. 216-225.

8. K. D. Squire, "Changing the game: What happens when video games enter the classroom," Innov. J. online Educ., vol. 1, no. 6, pp. 1829-1841, 2005.

9. C. Stieler-Hunt and C. M. Jones, "A Model for Exploring the Usefulness of Games for Classrooms," in Proceedings of the 2015 DiGRA International Conference, 2015.

10. M.-M. Popescu, I. Roceanu, J. Earp, M. Ott, and P. Moreno-Ger, "Aspects of Serious Games Curriculum Integration - A Two-Folded Approach," 8th Int. Sci. Conf. eLearning Softw. Educ., pp. 359-366, 2012.

11. J. R. Feinberg, "Debriefing in simulation games: An examination of reflection on cognitive and affective learning outcomes," University of Georgia, 2003.

12. B. Kim, H. Park, and Y. Baek, "Not just fun, but serious strategies: Using meta-cognitive strategies in game-based learning," Comput. Educ., vol. 52, no. 4, pp. 800-810, 2009.

13. B. Sawyer and P. Smith, "Serious Games Taxonomy," in Game Developers Conference, 2008.

14. D. Djaouti, J. Alvarez, and J.-P. Jessel, "Classifying serious games: The G/P/S model," in Handbook of research on improving learning and motivation through educational games: Multidisciplinary approaches, no. 2005, 2011, pp. 118-136.

15. F. Imbeault, B. Bouchard, and A. Bouzouane, "Serious Games in Cognitive Training for Alzheimer's Patients," in IEEE 1st International Conference on Serious Games and Applications for Health (SeGAH), 2011, pp. 1-8.

16. H. M. Zakari, M. Ma, and D. Simmons, "A Review of Serious Games for Children with Autism Spectrum Disorders (ASD)," in Serious Games Development and Applications, Springer International Publishing, 2014, pp. 93-106.

17. B. Yuan and E. Folmer, "Blind hero: enabling guitar hero for the visually impaired," in Proceedings of the 10th international ACM SIGACCESS conference on Computers and accessibility, 2008, pp. 169-176.

18. T. Morelli, J. Foley, L. Columna, L. Lieberman, and E. Folmer, "VI-Tennis : a Vibrotactile I Audio Exergame for Players who are Visually Impaired Categories and Subject Descriptors," in Foundations of Digital Games, 2010, pp. 147-154.

19. A. Whitehead, H. Johnston, N. Nixon, and J. Welch, "Exergame effectiveness: what the numbers can tell us," in Proceedings of the 5th ACM SIGGRAPH Symposium on Video Games, 2010, pp. 55-62.

20. H. Song, W. Peng, and K. M. Lee, "Promoting exercise self-efficacy with an exergame.," $J$. Health Commun., vol. 16, pp. 148-162, 2011.

21. N. Degens and E. Braad, "Keep on Moving: Designing a Physiotherapeutic Exergame for Different Devices and Exercises," in DiGRA 2015: Diversity of Play, 2015.

22. C. Swain, "Designing Games to Effect Social Change," in Situated Play, Proceedings of DiGRA 2007 Conference, 2007, pp. 805-809.

23. I. Bogost, Persuasive games: The expressive power of videogames. MIT Press, 2007.

24. F. Khatib, S. Cooper, M. D. Tyka, K. Xu, I. Makedon, Z. Popovic, and D. Baker, "Algorithm discovery by protein folding game players.," in Proceedings of the National Academy of Sciences, 2011, vol. 108, no. 47, pp. 18949-18953.

25. K. Kraiger, K. Ford, and E. Salas, "Application of Cognitive, Skill-Based, and Affective Theories of Learning Outcomes to New Methods of Training Evaluation," J. Appl. Psychol., vol. 78, no. 2, pp. 311-328, 1993. 
26. A. Azadegan, S. Sutherland, and C. Harteveld, "Design Approach for Collaborative Decision Making Games," in Foundations of Digital Games, 2015.

27. S. Barab, M. Thomas, T. Dodge, R. Carteaux, and H. Tuzun, "Making learning fun: Quest Atlantis, a game without guns," Educ. Technol. Res. Dev., vol. 53, no. 1, pp. 86-107, 2005.

28. S. Barab, T. Dodge, H. Tuzun, K. Job-Sluder, C. Jackson, A. Arici, L. Job-Sluder, R. Carteaux, J. Gilbertson, and C. Heiselt, "The Quest Atlantis Project: A Socially-Responsive Play Space for Learning," in The Design and Use of Simulation Computer Games in Education, 2007, pp. 153-180.

29. M. K. Thomas, S. Barab, and H. Tuzun, "Developing Critical Implementations of Technology-Rich Innovations: A Cross-Case Study of the Implementation of Quest Atlantis," J. Educ. Comput. Res., vol. 41, no. 2, pp. 125-153, 2009.

30. R. Khaled and G. Ingram, "Tales from the front lines of a large-scale serious game project," in Proceedings of the 2012 ACM annual conference on Human Factors in Computing Systems - CHI '12, 2012, pp. 69-78.

31. M. Molenda, "In search of the elusive ADDIE model," Perform. Improv., vol. 42, no. 5, pp. 34-37, 2003.

32. W. Westera, R. J. Nadolski, H. G. K. Hummel, and I. G. J. H. Wopereis, "Serious games for higher education: a framework for reducing design complexity," J. Comput. Assist. Learn., vol. 24 , no. 5 , pp. 420-432, 2008.

33. T. Olsen, K. Procci, and C. Bowers, "Serious Games Usability Testing: How to Ensure Proper Usability, Playability, and Effectiveness," vol. 6770, no. September 2015, 2011.

34. C. Keith, Agile Game Development with Scrum. Pearson Education, 2010.

35. S. Barab and K. D. Squire, "Design-Based Research: Putting a Stake in the Ground," $J$. Learn. Sci., vol. 13, no. 1, pp. 1-14, 2004.

36. J. H. G. Klabbers, "Gaming and Simulation: Principles of a Science of Design," Simul. Gaming, vol. 34, pp. 569-591, 2003.

37. B. Bannan-Ritland, "The Role of Design in Research: The Integrative Learning Design Framework," Educ. Res., vol. 32, no. 1, pp. 21-24, 2003.

38. A. Faiola, S. Boyd Davis, and R. L. Edwards, "Extending knowledge domains for new media education: integrating interaction design theory and methods.," New Media Soc., vol. 12, no. 5, pp. 691-709, 2010.

39. A. R. Hevner, "A Three Cycle View of Design Science Research A Three Cycle View of Design Science Research,” Scand. J. Inf. Syst., vol. 19, no. 2, pp. 87-92, 2007.

40. A. R. Hevner, S. T. March, and J. Park, "Design Science in Information Systems Research," MIS Q., vol. 28, no. 1, pp. 75-105, 2004.

41. I. Mayer, G. Bekebrede, C. Harteveld, H. Warmelink, Q. Zhou, T. Van Ruijven, J. Lo, R. Kortmann, and I. Wenzler, "The research and evaluation of serious games: Toward a comprehensive methodology,” Br. J. Educ. Technol., vol. 45, no. 3, pp. 502-527, 2014.

42. Y. A. Rankin, M. McNeal, M. W. Shute, and B. Gooch, "User centered game design: evaluating massive multiplayer online role playing games for second language acquisition," in Proceedings of the 2008 ACM SIGGRAPH symposium on Video games, 2008, pp. 43-49.

43. R. Khaled and A. Vasalou, "Bridging serious games and participatory design," Int. J. ChildComputer Interact., vol. 2, no. 2, pp. 93-100, 2014.

44. K. Mitgutsch and N. Alvarado, "Purposeful by Design: A Serious Game Design Assessment Framework," in Proceedings of the International Conference on the Foundations of Digital Games, FDG '12, 2012, pp. 121-128.

45. T. Fullerton, Game Design Workshop - A Playcentric Approach to Creating Innovative Games, Third edit. CRC Press, 2014. 
46. T. Sigman, "The Siren Song of the Paper Cutter: Tips and Tricks from the Trenches of Paper Prototyping," Gamasutra, 2005. [Online]. Available: http://www.gamasutra.com/view/feature/130814/the_siren_song_of_the_paper_php.

47. D. Church, "Formal Abstract Design Tools," Gamasutra, 1999. [Online]. Available: http://www.gamasutra.com/view/feature/131764/formal_abstract_design_tools.php.

48. G. Costikyan, "I Have No Words but I Must Design: Toward a Critical Vocabulary for Games," in Computer Games and Digital Cultures Conference, 2002, pp. 9-33.

49. R. Koster, “A Grammar of Gameplay,” Game Developers Conference, 2005. [Online]. Available: http://www.theoryoffun.com/grammar/gdc2005.htm.

50. S. Björk and J. Holopainen, Patterns in Game Design. Boston, MA: Charles River Media, 2005.

51. J. Dormans, "Engineering Emergence - Applied Theory for Game Design," University of Amsterdam, 2012.

52. P. Rooney, "A Theoretical Framework for Serious Game Design: Exploring Pedagogy, Play and Fidelity and their Implications for Design Process," Int. J. Game-Based Learn., vol. 2, no. 4, pp. 41-60, 2012.

53. N. Degens, I. Bril, and E. Braad, "A Three-Dimensional Model for Educational Game Analysis \& Design," in Foundations of Digital Games, 2015.

54. M. G. Wagner and T. Wernbacher, "Iterative Didactic Design of Serious Games," in 1st International Workshop on Intelligent Digital Games for Empowerment and Inclusion, 2013.

55. M. Barton, C. Symborski, M. Quinn, C. K. Morewedge, K. S. Kassam, and J. H. Korris, "The Use of Theory in Designing a Serious Game for the Reduction of Cognitive Biases," in DiGRA 2015: Diversity of Play, 2015.

56. E. J. Marchiori, Á. Serrano, Á. Del Blanco, I. Martinez-Ortiz, and B. Fernández-Manjón, "Integrating domain experts in educational game authoring: A case study," in Proceedings 2012 4th IEEE International Conference on Digital Game and Intelligent Toy Enhanced Learning, DIGITEL 2012, 2012, pp. 72-76.

57. W. Ryan and D. Charsky, "Integrating Serious Content into Serious Games," in Foundations of Digital Games, 2013.

58. L. E. Nacke, A. Drachen, K. Kuikkaniemi, J. Niesenhaus, H. Korhonen, W. M. Van den Hoogen, K. Poels, W. A. IJsselsteijn, and Y. A. W. De Kort, "Playability and Player Experience Research," in Proceedings of the IEEE BT - Breaking New Ground: Innovation in Game, 2009, pp. 1-11.

59. H. Kelly, K. Howell, E. Glinert, L. Holding, C. Swain, A. Burrowbridge, and M. Roper, "How to build serious games," Commun. ACM, vol. 50, p. 44, 2007.

60. E. P. Braad, J. Folkerts, and N. Jonker, "Attributing Design Decisions in the Evaluation of Game-Based Health Interventions," in Proceedings of the 3rd European Conference on Gaming and Playful Interaction in Health Care, 2013, pp. 61-74.

61. M. A. Adams, S. J. Marshall, L. Dillon, S. Caparosa, E. Ramirez, J. Phillips, and G. J. Norman, "A theory-based framework for evaluating exergames as persuasive technology," in Proceedings of the 4th International Conference on Persuasive Technology - Persuasive '09, 2009 , p. 1.

62. F. Bellotti, B. Kapralos, K. Lee, P. Moreno-Ger, and R. Berta, "Assessment in and of serious games: An overview," Adv. Human-Computer Interact., no. 1, 2013.

63. A. Drachen and S. Göbel, "Methods for Evaluating Gameplay Experience in a Serious Gaming Context," Int. J. Comput. Sci. Sport, vol. 9, pp. 1-12, 2010. 
64. W. IJsselsteijn, Y. De Kort, K. Poels, A. Jurgelionis, and F. Bellotti, "Characterising and Measuring User Experiences in Digital Games," in International Conference on Advances in Computer Entertainment Technology, 2007, vol. 620, pp. 1-4.

65. K. M. Gerling, F. P. Schulte, and M. Masuch, "Designing and evaluating digital games for frail elderly persons," in Proceedings of the 8th International Conference on Advances in Computer Entertainment Technology - ACE '11, 2011, p. 1.

66. F. De Grove, J. Van Looy, and C. Courtois, "Towards a Serious Game Experience Model: Validation, Extension and Adaptation of the GEQ for Use in an Educational Context," Play. Play. Exp., vol. 10, pp. 47-61, 2010.

67. M. Eagle and T. Barnes, "Experimental evaluation of an educational game for improved learning in introductory computing," in Proceedings of the 40th ACM technical symposium on Computer science education - SIGCSE '09, 2009, p. 321.

68. Á. Serrano, E. J. Marchiori, Á. Del Blanco, J. Torrente, and B. Fernández-Manjón, “A framework to improve evaluation in educational games," in IEEE Global Engineering Education Conference, EDUCON, 2012.

69. Á. Serrano-Laguna, J. Torrente, P. Moreno-Ger, and B. F. Manjón, "Tracing a little for big improvements: Application of learning analytics and videogames for student assessment," Procedia Comput. Sci., vol. 15, pp. 203-209, 2012.

70. S. E. Kirkley, S. Tomblin, and J. Kirkley, "Instructional Design Authoring Support for the Development of Serious Games and Mixed Reality Training Instructional Design Authoring Support for the Development of Serious Games and Mixed Reality Training," in Interservice/Industry Training, Simulation and Education Conference (I/ITSEC)., 2005, pp. $1-11$.

71. J. Kirkley, S. E. Kirkley, and J. Heneghan, "Building Bridges Between Serious Game Design and Instructional Design," in The Design and Use of Simulation Computer Games in Education, B. E. Shelton and D. A. Wiley, Eds. 2007, pp. 59-82.

72. R. B. Moser, "A Methodology for the Design of Educational Computer Adventure Games," 2000.

73. S. Chen, Z. Pan, M. Zhang, and H. Shen, "A case study of user immersion-based systematic design for serious heritage games," Multimed. Tools Appl., vol. 62, no. 3, pp. 633-658, 2013.

74. S. De Freitas and S. Jarvis, "Towards a Development Approach to Serious Games," GamesBased Learn. Adv. Multi-Sensory Hum. Comput. Interfaces Tech. Eff. Pract., pp. 215-231, 2009.

75. T. W. Malone, "What Makes Things Fun to Learn? A Study of Intrinsically Motivating Computer Games," 1980.

76. T. W. Malone, "Toward a Theory of Intrinsically Motivating Instruction," Cogn. Sci. A Multidiscip. J., vol. 5, pp. 333-369, 1981.

77. E. L. Deci and R. M. Ryan, "The 'what' and 'why' of goal pursuits: Human needs and the self-termination of behavior.," Psychol. Inq., vol. 11, pp. 227-268, 2000.

78. R. M. Ryan, C. S. Rigby, and A. Przybylski, "The motivational pull of video games: A selfdetermination theory approach," Motiv. Emot., vol. 30, pp. 347-363, 2006.

79. A. K. Przybylski, C. S. Rigby, and R. M. Ryan, "A motivational model of video game engagement.," Rev. Gen. Psychol., vol. 14, no. 2, pp. 154-166, 2010.

80. R. Garris, R. Ahlers, and J. E. Driskell, "Games, Motivation, and Learning: A Research and Practice Model," Simul. Gaming, vol. 33, no. 4, pp. 441-467, 2002.

81. G. Gunter, R. F. Kenny, and E. H. Vick, "A Case for a Formal Design Paradigm for Serious Games,” J. Int. Digit. Media Arts Assoc., vol. 3, no. 2004, pp. 1-19, 2006. 
82. J. M. Keller and T. W. Kopp, "Application of the ARCS model to motivational design.," in Instructional theories in action: Lessons illustrating selected theories., C. M. Reigeluth, Ed. New York: Larence Erlbaum, 1987, pp. 289-320.

83. R. Gagne, Domains of Learning. 1971.

84. G. Gunter, R. F. Kenny, and E. H. Vick, "Taking educational games seriously: Using the RETAIN model to design endogenous fantasy into standalone educational games," Educ. Technol. Res. Dev., vol. 56, pp. 511-537, 2008.

85. B. Paras and J. Bizzochi, "Game, motivation, and effective learning: An integrated model for educational game design." 2005.

86. K. Kiili, "Digital game-based learning: Towards an experiential gaming model," Internet High. Educ., vol. 8, pp. 13-24, 2005.

87. D. Kolb, Experiential learning: experience as the source of learning and development. New Jersey: Prentice-Hall, 1984.

88. A. Amory, "Game object model version II: A theoretical framework for educational game development," Educ. Technol. Res. Dev., vol. 55, no. 1, pp. 51-77, 2007.

89. S. Arnab, T. Lim, M. B. Carvalho, F. Bellotti, S. de Freitas, S. Louchart, N. Suttie, R. Berta, and A. De Gloria, "Mapping learning and game mechanics for serious games analysis," Br. J. Educ. Technol., 2014.

90. W. L. Bedwell, D. Pavlas, K. Heyne, E. H. Lazzara, and E. Salas, "Toward a Taxonomy Linking Game Attributes to Learning: An Empirical Study," Simul. Gaming, vol. 43, no. 6, pp. 729-760, 2012.

91. A. Boyan and J. L. Sherry, "The Challenge in Creating Games for Education: Aligning Mental Models With Game Models," Child Dev. Perspect., vol. 5, no. 2, pp. 82-87, 2011.

92. M. P. J. Habgood and S. E. Ainsworth, "Motivating children to learn effectively: exploring the value of intrinsic integration in educational games," J. Learn. Sci., vol. 20, no. 2, pp. 169-206, Apr. 2011.

93. M. B. Carvalho, F. Bellotti, R. Berta, A. De Gloria, C. I. Sedano, J. B. Hauge, J. Hu, and M. Rauterberg, "An activity theory-based model for serious games analysis and conceptual design," Comput. Educ., 2015.

94. S. de Freitas and M. Oliver, "How can exploratory learning with games and simulations within the curriculum be most effectively evaluated?," Comput. Educ., vol. 46, pp. 249-264, 2006.

95. S. De Freitas and J.-P. Van Staalduinen, "A Game Based Learning Framework Linking Game Design and Learning Outcomes," Learn. to Play Explor. Futur. Educ. with Video Games, pp. 1-37, 2009.

96. B. E. Shelton and D. A. Wiley, The design and use of simulation computer games in education, vol. 21, no. 2. 2007.

97. B. Marne, J. Wisdom, B. Huynh-Kim-Bang, and J. Labat, "The six facets of serious game design: a methodology enhanced by our design pattern library," in 21st Century Learning for 21 st Century Skills, A. Ravenscroft, S. Lindstaedt, C. D. Kloos, and D. Hernández-Leo, Eds. Berlin-Heidelberg: Springer, 2012, pp. 208-221.

98. P. Wouters, C. van Nimwegen, H. van Oostendorp, and E. D. van der Spek, "A meta-analysis of the cognitive and motivational effects of serious games.," J. Educ. Psychol., vol. 105, pp. 249-265, 2013.

99. M. S. O. Almeida and F. S. C. Silva, "A Systematic Review of Game Design Methods and Tools," in Entertainment Computing ICEC 2013 SE, J. Anacleto, E. G. Clua, F. S. C. Silva, S. Fels, and H. Yang, Eds. Berlin-Heidelberg: Springer, 2013, pp. 17-29.

100. K. Neil, "Game design tools: Time to evaluate," in Proceedings of 2012 DiGRA Nordic, 2012. 
101. B. Huynh-Kim-Bang, J. Wisdom, and J.-M. Labat, "Design Patterns in Serious Games: A Blue Print for Combining Fun and Learning Introduction," 2010.

102. C. Dormann, J. R. Whitson, and M. Neuvians, "Once More With Feeling: Game Design Patterns for Learning in the Affective Domain," Games Cult., vol. 8, pp. 215-237, 2013.

103. C. Alexander, S. Ishikawa, and M. Silverstein, "A Pattern Language: Towns, Buildings, Construction," Structure, vol. 2, 1977.

104. E. Gamma, R. Helm, R. Johnson, and J. Vlissides, "Design Patterns: Abstraction and Reuse of Object-Oriented Design," Games Cult., vol. 8, no. 4, pp. 215-237, 2013.

105. B. Kreimeier, J. Holopainen, and S. Björk, "Game Design Patterns," in Lecture Notes from GDC 2003, 2003.

106. B. Kreimeier, "The Case for Game Design Patterns," Gamasutra, 2003.

107. S. Björk, S. Lundgren, and J. Holopainen, "Game design patterns," in Proceedings of Level Up-1st International Digital Games Research Conference, 2003, pp. 180-193.

108. S. Kelle, Game Design Patterns for Learning. 2012.

109. J. Cheng, C. Putnam, and D. C. Rusch, "Towards Efficacy-Centered Game Design Patterns for Brain Injury Rehabilitation: A Data-Driven Approach," in Proceedings of the 17th International ACM SIGACCESS Conference on Computers \& Accessibility, 2015, pp. 291299.

110. C. Reuter, V. Wendel, S. Göbel, and R. Steinmetz, "Game Design Patterns for Collaborative Player Interactions," DiGRA 2014, 2014.

111. G. Žavcer, S. Mayr, and P. Petta, "Design Pattern Canvas: Towards Co-Creation of Unified Serious Game Design Patterns," in VS-Games 2014: 6th International Conference on Games and Virtual Worlds for Serious Applications, 2014, pp. 134-136.

112. R. Wetzel, "A Case for Design Patterns supporting the Development for Collaborative Player Interactions," in Foundations of Digital Games, 2013.

113. S. Dahlskog, J. Togelius, and S. Björk, "Patterns, dungeons and generators," in Proceedings of the 10th Conference on the Foundations of Digital Games, 2015.

114. S. Mader, S. Natkin, and G. Levieux, "How to analyse therapeutic games: the player/game/therapy model," Entertain. Comput. ICEC, pp. 193-206, 2012.

115. E. A. Holmes, E. L. James, T. Coode-Bate, and C. Deeprose, "Can playing the computer game 'Tetris' reduce the build-up of flashbacks for trauma? A proposal from cognitive science," PLoS One, vol. 4, no. 1, pp. 41-53, 2009.

116. A. Osterwalder and Y. Pigneur, Business Model Generation: A Handbook for Visionaries, Game Changers, and Challengers. Wiley, 2010. 